\title{
Restauração do diafragma de felino com enxerto autólogo de pericárdio ${ }^{1}$
}

\author{
Saulo Tadeu Lemos Pinto Filho ${ }^{2}$ \\ Juliana Tabarelli Brondani ${ }^{3}$ \\ Dominguita Lühers Graça ${ }^{4}$ \\ João Eduardo Schossler
}

\begin{abstract}
Pinto Filho STL, Brondani JT, Graça DL, Schossler JE. Restauração do diafragma de felino com enxerto autólogo de pericárdio. Acta Cir Bras [serial online] 2003 Set-Out;18(5). Disponível em URL: http://www.scielo.br/acb.

RESUMO - Objetivo: Avaliar o uso de enxerto autólogo de pericárdio para correção de defeitos diafragmáticos em felinos. Métodos: Foram utilizados doze gatos domésticos, adultos, sem raça definida, pesando entre dois e quatro quilogramas. O procedimento cirúrgico consistiu de toracotomia no 7ํe espaço intercostal esquerdo, remoção de um retalho do pericárdio de, aproximadamente, 2,0 $\mathrm{x} 4,0 \mathrm{~cm}$ e sutura desse em um defeito de tamanho aproximado criado no diafragma. Cinco animais foram observados por um período de 30 dias de pós-operatório e o restante em 60 dias, quando foram submetidos à eutanásia para observação macroscópica e coleta de amostras para avaliação histológica. Resultados: Foi observada nos animais do grupo de 30 dias, substituição parcial e no grupo de 60 dias, substituição total do enxerto de pericárdio por tecido fibrovascular, permitindo o restabelecimento completo do diafragma. Macroscopicamente, foi verificada presença de aderência na cavidade torácica, com o pulmão e pleura parietal e, na cavidade abdominal, com o fígado e omento, porém, sem comprometimento clínico das estruturas envolvidas. Conclusão: O enxerto autólogo felino pode ser utilizado para reparação de defeitos diafragmáticos, pois suporta a diferença de pressão presente, sendo substituído por tecido cicatricial, sem apresentar sinais clínicos e histológicos de rejeição.

DESCRITORES - Tórax. Cirurgia. Gato. Enxerto.
\end{abstract}

\section{Introdução}

A incidência de hérnia diafragmática em medicina veterinária é relativamente alta, sendo o traumatismo a causa mais comum em cães e gatos, principalmente por acidentes automobilísticos ${ }^{1,2}$.

Os defeitos diafragmáticos geralmente culminam com a formação de hérnias, ocasionando alterações circulatórias e respiratórias, podendo levar a óbito, se procedimentos clínico-cirúrgicos não forem realizados. Nos casos, tanto de origem congênita ou traumática, que se impedem a aproximação das bordas do defeito, é indicada a utilização de implantes biológicos ou protéticos ${ }^{3}$.

Quando utilizado o reparo com enxerto cutâneo livre, em cães, os autores não observaram alterações fisiológicas nos órgãos relacionados. Em 3\% dos animais, aproximadamente, observou-se a ocorrência de severa infecção e retração do enxerto em quatro meses. A microscopia demonstrou degeneração dos folículos pilosos com presença de pequenas áreas

1. Trabalho realizado na Universidade Federal de Santa Maria (UFSM).

2. Médico Veterinário, Mestre, Professor Assistente da Faculdade de Zootecnia, Veterinária e Agronomia (FZVA) da PUCRS, Uruguaiana - RS.

3. Médico Veterinário, Mestrando em Anestesiologia, Programa de Pós-graduação em Medicina Veterinária, Centro de Ciências Rurais (CCR), Universidade Federal de Santa Maria (UFSM), Santa Maria - RS.

4. Médico Veterinário, PhD, Prof. Titular do Departamento de Patologia, CCR, UFSM.

5. Médico Veterinário, Doutor, Prof. Adjunto do Departamento de Clínica de Pequenos Animais, CCR, UFSM. 
granulomatosas, células inflamatórias e raros microabs$\operatorname{cessos}^{4}$.

Schairer e Keeley ${ }^{5}$ fizeram uso experimental de enxerto homólogo de fáscia lata no reparo de defeitos diafragmáticos em cães. Foi verificada a presença de reação inflamatória com presença de fibrina e infiltração celular no local do enxerto por curto período de tempo, observando-se oclusão total do defeito provocado. Já Faria e col. ${ }^{6}$ empregaram para correção de defeito no diafragma de cães, transposição do músculo reto do abdome. Os autores verificaram uma perfeita integração tecidual entre o músculo reto do abdome e diafragma com total oclusão do defeito diafragmático e formação de tecido de granulação. No entanto, apresenta limitação quanto a sua largura, não podendo ser usado em defeitos largos. Quanto ao comprimento, é um músculo longo o suficiente para corrigir defeitos dorso-craniais do diafragma através da cavidade abdominal.

Um retalho pediculado do músculo grande dorsal foi utilizado por Oliveira e col. ${ }^{7}$ para reparar um defeito diafragmático experimental em cães. Foram verificadas uma reação inflamatória e crescimento de tecido conjuntivo, caracterizando a resposta cicatricial do diafragma com o enxerto, apresentando boa consolidação da sutura. Assim, os autores concluíram que o retalho pediculado do músculo grande dorsal é uma opção para a correção de grandes defeitos diafragmáticos em cães.

Outros estudos empregaram para reparação de defeito diafragmático de cães, enxerto autólogo do músculo transverso do abdome associado ao peritônio. Foi verificado macroscopicamente pelos autores uma boa integração peritônio-muscular com a porção músculo-tendinosa do diafragma em todos os animais testados. Também constatou-se a formação de fibras colágenas e de tecido fibroso, demostrando ser uma técnica eficiente para reconstituição de defeitos diafragmáticos ${ }^{8}$. Fossum ${ }^{1}$ também recomenda o uso de enxerto autólogo de músculo transverso do abdome juntamente com peritônio, para correção de defeitos diafragmáticos crônicos em cães.

No começo da década de 90, Ranzani e col. ${ }^{9}$ avaliaram o implante de pericárdio de eqüino preservado em glicerina para oclusão de solução de continuidade no segmento muscular em diafragma de cão. Os autores verificaram que o enxerto não desencadeou manifestações clínicas nos animais operados e foi eficaz na obstrução do orifício induzido. $\mathrm{O}$ fragmento implantado permite a neoformação de membrana fibrosa que oclui a solução de continuidade, não restringindo a função diafragmática.

Em 1982 foi testado por GALLO e col. ${ }^{10}$, pericárdio de bovino e suíno conservado em solução de glutaraldeído para reparação de defeitos diafragmáticos de cães. Os autores após acessarem o diafragma de 9 cães pelo $7^{\circ}$ espaço intercostal direito e em 6 cães, pelo esquerdo, fixaram em 4 cães um segmento de pericárdio bovino e, em 11 cães, pericárdio suíno. Os resultados demonstraram boa vedação do defeito diafragmático, sendo histologicamente observada presença de uma camada de tecido conjuntivo sobre o enxerto tanto de pericárdio bovino como suíno.

Mazzanti e col. ${ }^{11}$ estudaram o comportamento do músculo diafragma homólogo conservado em solução supersaturada de açúcar a 300\% para reparação de grande defeito no diafragma de cão. Foi verificado que as fibras musculares do implante foram quase totalmente substituídas por tecido de granulação, com completa união das bordas do defeito diafragmático. Os autores concluíram que o segmento de músculo diafragma mantido em solução supersaturada de açúcar a 300\%, em temperatura ambiente, por um período não inferior a 30 dias, conserva sua estrutura e não induz reações de rejeição pelo tecido receptor, quando utilizado como homoimplante.

Eurides e col. ${ }^{12}$ estudaram comparativamente o comportamento do tecido diafragmático nas suturas com fios de algodão e poliglactina em cães. Verificaram que o polyvicryl suporta a ação mecânica do músculo diafragma provocando discreta reação inflamatória, mostrando-se superior ao algodão, sendo adequado para reparação de hérnias diafragmáticas. Mais recentemente, Cunha e col. ${ }^{13}$ usaram poliglactina 910 para redução de hérnia peritôneo-pericárdica em cão. Verificaram a manutenção da tensão por longo período de tempo (90 dias) sem ocorrência de recidiva, mostrando-se eficiente na síntese de defeitos peritôneo-pericárdicos no cão.

O objetivo do experimento é avaliar o comportamento de um retalho autólogo de pericárdio na restauração de defeito no músculo diafragma de felino, mediante análise macro e microscópica da área de enxertia.

\section{Métodos}

Foram utilizados doze gatos domésticos, adultos, clinicamente sadios, sem raça definida, machos e fêmeas com peso variando de 2 a 4 quilogramas, oriundos do Biotério Central da Universidade Federal de Santa Maria. Os animais foram separados em dois grupos para avaliação até 30 dias (grupo 1) e 60 dias (grupo 2) de pós-operatório. Esses animais foram observados por um período de uma semana (sete dias) e, após serem desverminados, mantidos em gaiolas individuais com alimentação e água ad libitum. Após jejum prévio de 12 horas, os animais foram tranqüilizados com butorfanol ${ }^{\mathrm{a}}$ na dose de $0,4 \mathrm{mg} / \mathrm{kg}$, tramadol $^{\mathrm{b}}$ 
$(2,0 \mathrm{mg} / \mathrm{kg})$ e sulfato de atropina ${ }^{\mathrm{c}}(0,04 \mathrm{mg} / \mathrm{kg})$, via intramuscular. Posteriormente, foi realizada depilação na região torácica esquerda e, após indução anestésica com propofol ${ }^{\mathrm{d}}$ na dose de $6 \mathrm{mg} / \mathrm{kg}$ via intravenosa. A manutenção anestésica foi feita através de intubação oro-traqueal, halotano ${ }^{\mathrm{e}}$ e ventilação por pressão positiva com oxigênio. Com os animais em decúbito lateral direito, realizou-se anti-sepsia do campo operatório com álcool-iodo-álcool.

A seguir, foi procedida toracotomia no $7^{\circ}$ espaço intercostal esquerdo, localização do coração e retirada de um retalho de pericárdio de, aproximadamente, 2,0 x 4,0 cm. Após, foi demarcada uma área do músculo diafragma esquerdo com quatro pontos de reparo de fio seda 3- $0^{\mathrm{f}}$ em cada ângulo do defeito com as mesmas dimensões citadas acima que foi removida com tesoura em seguida. O segmento de pericárdio autólogo fixouse às bordas do defeito diafragmático pelos quatro pontos anteriormente empregados como reparos. $\mathrm{Na}$ seqüência, a fixação do enxerto foi completada utilizando sutura contínua simples e poliglactina 910 5-0 e os reparos removidos (Figura 1).

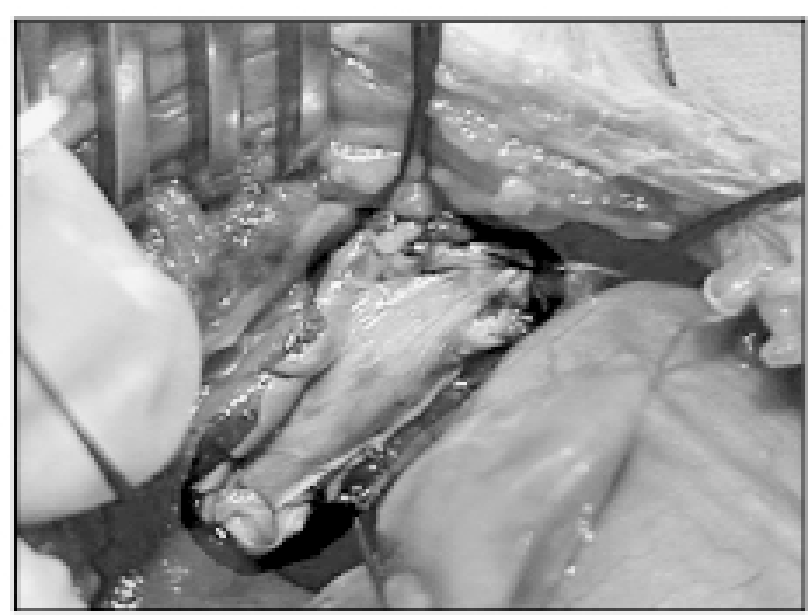

FIGURA 1 - Aspecto do defeito diafragmático após a colocação do enxerto.

A toracorrafia foi realizada com pontos simples contínuos de fio poliamida 0,25 , sendo de pele, pontos isolados simples utilizando o mesmo tipo de fio. $\mathrm{O}$ restabelecimento da pressão negativa intratorácica ocorreu no terço médio do $8^{\circ}$ espaço intercostal com escalpe 19G, conectado a seringa de $60 \mathrm{ml}$ por meio de torneira de 3 vias.

Foram utilizados ampicilina sódica $(20 \mathrm{mg} / \mathrm{kg}, \mathrm{IV})$, trinta minutos antes do início da cirurgia e cetoprofeno ${ }^{\mathrm{h}}$ (2 mg/kg, IV) logo após o término da cirurgia e, por via subcutânea, durante mais quatro dias $(1 \mathrm{mg} / \mathrm{kg})$.

No pós-operatório, a ferida cutânea foi submetida a curativo local com gaze e solução fisiológica de $\mathrm{NaCl}$
$0,9 \%$ durante sete dias e, após, removidos os pontos de pele.

Os animais foram observados diariamente e avaliados clinicamente, sendo o grupo $1(\mathrm{G} 1)$ até o $30^{\circ}$ dia de pós-operatório e o grupo 2 (G2), até o $60^{\circ}$ dia, quando foram submetidos à eutanásia para avaliação macroscópica e coleta de fragmentos para estudo em microscopia óptica da área de enxertia. Os cortes histológicos foram corados pela técnica de hematoxilina-eosina (HE).

\section{Resultados}

Todos os animais apresentaram boa evolução clínica no período de observação pós-operatória sem a ocorrência de óbito e deiscência da ferida costal ou evidência clínica de solução de continuidade no diafragma, demonstrando boa evolução operatória.

O protocolo anestésico utilizado nesse experimento foi eficiente, permitindo a realização das manobras cirúrgicas exigidas em cada procedimento.

A via de acesso utilizada nesse experimento, no $7^{\circ}$ espaço intercostal esquerdo, permitiu a visualização, bem como a manipulação das estruturas envolvidas no procedimento.

O emprego dos pontos de reparo em cada ângulo do defeito diafragmático facilitou o posicionamento e a sutura do enxerto pericárdico no local.

Nesse experimento, o fio de sutura utilizado foi a poliglactina $910 \mathrm{n}^{\circ} 5-0$, que demonstrou ser seguro, suportando a diferença de pressão exercida sobre o diafragma.

O método utilizado para reposição da pressão negativa intratorácica, utilizando escalpe $19 \mathrm{G}$ conectado a uma seringa de $60 \mathrm{ml}$ através de torneira de três vias, foi eficiente para evitar um possível pneumotórax residual, conforme observado clinicamente.

A dimensão do defeito diafragmático empregada no experimento, de 2,0 x 4,0 cm, para implantação de um retalho autólogo de pericárdio, permitiu avaliar o comportamento cicatricial e a resistência do enxerto no músculo diafragma.

Nesse experimento, foram observadas nos animais do grupo 1 (30 dias de pós-operatório), aderências entre a área enxertada e os órgãos abdominais e torácicos adjacentes. Entre as estruturas abdominais, o fígado foi o único órgão a apresentar aderência (50\%) (Figura 2A) e entre as torácicas, a pleura parietal costal apresentou maior índice aderência (50\%) (Figura 2B) seguida do pulmão esquerdo $(33,3 \%)$. Nos animais do grupo 2 (60 dias de pós-operatório) observaram-se 
índices maiores de aderência com estruturas abdominais e torácicas. Entre as abdominais, com o fígado $(83,3 \%)$ seguido pelo omento $(16,6 \%)$ e entre as torácicas com a pleura parietal costal $(66,6 \%)$ e pulmão esquerdo $(33,3 \%)$ (Tabela 1). No animal $n^{\circ} 6$ do grupo 2 (60 dias) não foi observada nenhuma aderência abdominal ou torácica. Em três animais $(50 \%)$ do grupo $1\left(n^{\text {os }} 3\right.$, 5 e 6) apresentaram aderência pulmonar com a linha de incisão torácica, porém não manifestaram sinais clínicos decorrentes dessa alteração (Figura 2C).
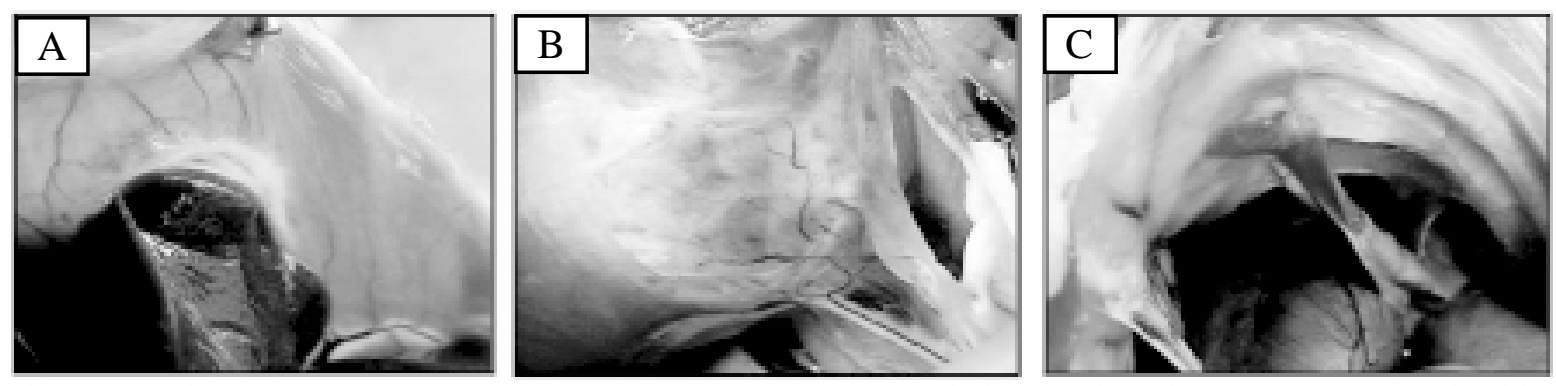

FIGURA 2 - (A) Aderência do fígado com a área de enxertia, (B) Aderência da pleura costal com a área de enxertia, (C) A aderência do pulmão esquerdo com a linha de incisão da toracotomia.

TABELA 1 - Restauração do diafragma felino com enxerto autólogo de pericárdio. Número de aderências entre estruturas abdominais e torácicas com a área de enxertia, decorridos 30 e 60 dias de pós-operatório.

\begin{tabular}{ccccc}
\hline & \multicolumn{2}{c}{ Estruturas abdominais } & \multicolumn{2}{c}{ Estruturas torácicas } \\
\hline Grupos & Fígado & Omento & Pulmão & Pleura costal \\
\hline G1- 30 dias & 03 & - & 02 & 03 \\
& $(50 \%)$ & & $(33,3 \%)$ & $(50 \%)$ \\
\hline G2- 60 dias & 05 & 01 & 02 & 04 \\
& $(83,3 \%)$ & $(16,6 \%)$ & $(33,3 \%)$ & $(66,6 \%)$ \\
\hline
\end{tabular}

$\mathrm{Na}$ avaliação macroscópica da área de enxertia, foi observada nos animais do G1 (30 dias), a formação de um anel de tecido fibrovascular na região de sutura e o preenchimento da área do implante por tecido translúcido fino (Figura 3A). Houve retração da ferida diafragmática em, aproximadamente, $30 \%$ em relação ao tamanho original. No gato $\mathrm{n}^{\circ} 6$ do G1 observou-se oclusão do defeito pela aderência abdominal de um lobo hepático e torácica por um lobo pulmonar separados por tecido fino e translúcido. Nos animais do G2 (60 dias) os resultados foram semelhantes ao G1, porém a retração era de, aproximadamente, $50 \%$ em relação ao tamanho original. $\mathrm{O}$ gato $\mathrm{n}^{\circ} 1$ do $\mathrm{G} 2$ manifestou resultado semelhante ao $\mathrm{n}^{\circ} 6$ do $\mathrm{G} 1$ e o $\mathrm{n}^{\circ} 2$ do $\mathrm{G} 2$ foi o único animal que apresentou aderência com o omento. Nos animais 1,3 e 4 do G1 não foram observadas aderências na cavidade abdominal.
Na avaliação microscópica da área de enxertia, no $30^{\circ}$ dia de pós-operatório $(\mathrm{G} 1)$, observou-se à presença de restos de fio envoltos por intensa reação piogranulomatosa (Figura 3B). Observou-se também regeneração muscular através da formação de células gigantes com vários núcleos, próximo à área de sutura, separadas por grande quantidade de tecido fibrovascular (Figura 3C). Os mesmos resultados foram observados no $60^{\circ}$ dia operatório (G2), porém com uma reação inflamatória mais branda e caracterizada pela presença de células musculares ligeiramente basofílicas e com menor número de núcleos, esses centrais e enfileirados (Figura 3D).

$\mathrm{Na}$ avaliação clínica dos animais de ambos os grupos, não foram observados sinais compatíveis com disfunção ou insuficiência respiratória, bem como, sinais de alteração cardíaca pela retirada do pericárdio. 


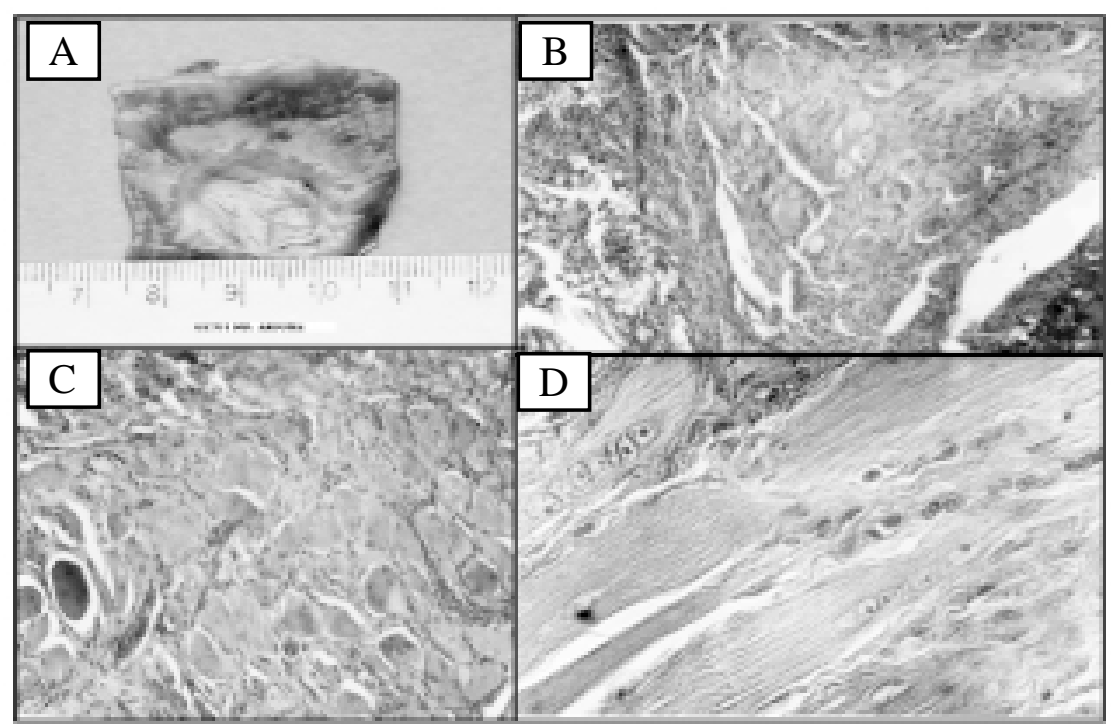

FIGURA 3 - (A) Aspecto macroscópico do diafragma decorridos 30 dias de pósoperatório, (B) Área de anastomose onde se observa reação ao fio de sutura (seta) e fibras musculares pálidas (cabeça de seta) com núcleos claros, alguns se organizando no centro das fibras, entremeados por tecido fibrovascular, (C) Reação do tecido muscular à transecção. Observam-se grupos de células gigantes separadas por tecido conjuntivo. 30 dias, obj. 10. HE., (D) Aspecto da área de anastomose após 60 dias de pós-operatório. Observar células musculares ligeiramente basofílicas e núcleos enfileirados. G1.60d.

\section{Discussão}

$\mathrm{O}$ acesso ao diafragma pelo $7^{\circ}$ espaço intercostal esquerdo, empregado nesse experimento, foi o mesmo empregado por Gallo e col. ${ }^{10}$, permitindo o acesso ao coração para retirada do saco pericárdico e a fixação do enxerto sobre o defeito diafragmático, com pouca interferência no campo cirúrgico durante a expansão pulmonar. Outras alternativas de acesso ao diafragma foram propostas como $8^{\circ}$ espaço intercostal empregado por Raiser ${ }^{14}$, laparotomia mediana utilizada por Ranzani e col. ${ }^{9}$, Faria e col. ${ }^{6}$ e paracostal por Eurides e col. ${ }^{8}$. A aplicação dessa técnica pelo $7^{\circ}$ espaço intercostal esquerdo, para restauração de defeitos diafragmáticos maiores que a dimensão utilizada, poderá inviabilizar o acesso ao diafragma, bem como a retirada de um segmento maior de pericárdio.

O uso de pontos de reparo foi de fundamental importância na aplicação da sutura definitiva, por permitir uma abordagem ao músculo diafragma, facilitando a manobra de sutura e evitando a manipulação excessiva no local, semelhante aos resultados encontrados por Eurides e col. ${ }^{8}$, utilizando peritôniomuscular autólogo e Mazzanti e col. ${ }^{11}$, músculo diafragma homólogo, na reparação de diafragma de cão.

A fixação do enxerto com sutura contínua simples foi utilizada nesse experimento pela facilidade, rapidez de aplicação e eficiente vedação pós-operatória do defeito diafragmático não permitindo o aparecimento de deiscências em nenhum animal, sendo também recomendada por Burton e White ${ }^{15}$.

Vários materiais de sutura foram empregados no reparo de defeitos diafragmáticos, como o náilon, utilizado por Mazzanti e col. ${ }^{3}$, polipropileno por Burton e White ${ }^{15}$, a seda utilizada por Faria e col..$^{6}$, o categute cromado, utilizado por Ranzani e col. ${ }^{9}$ e o ácido poliglicólico, por Gallo e col. ${ }^{10}$. Nesse experimento, o fio de sutura utilizado foi a poliglactina 910 , que demonstrou ser seguro suportando a diferença de pressão sobre o diafragma e de fácil manuseio, concordando com Eurides e col. ${ }^{8,12}$, Cunha e col. ${ }^{13}$ e Mazzanti e col. ${ }^{11}$. Na avaliação microscópica no $30^{\circ}$ dia de pós-operatório, verificou-se ao redor dos filamentos componentes do fio de sutura, infiltração intensa de polimorfonucleares neutrófilos e macrófagos, reação encontrada também por Eurides e col. ${ }^{8}$ e diferente da verificada por Mazzanti e col. ${ }^{11}$ que atribuiu a reação ao próprio enxerto e não ao fio de sutura.

A avaliação macroscópica da área de enxertia revelou, aos 30 dias de pós-operatório (G1) um anel de tecido fibrovascular na região da sutura maior que nos animais do G2; a oclusão do defeito era feita por tecido translúcido fino bem mais delgado nos animais do G1 quando comparado aos animais do G2. Isso demonstra que a intensa reação pio-granulomatosa ocorrida até 30 dias de pós-operatório foi promovida pelo fio de 
sutura e não pelo enxerto já que esse era autólogo, portanto, provocando menor ou nenhuma reação por parte do leito receptor. A retração da ferida ocorreu progressivamente conforme o tempo de pós-operatório devido ao fenômeno de contração das feridas, às custas de tecido de granulação, que a partir da periferia invadiu o enxerto, concordando com os achados de Ranzani e col. ${ }^{9}$. As aderências observadas tanto no G1 como no $\mathrm{G} 2$, por estruturas abdominais e torácicas podem ter impedido o músculo diafragma de sofrer contração efetiva durante a respiração porém, não foi observado nenhum tipo de sinal clínico pós-operatório compatível com disfunção ou insuficiência respiratória por parte dos animais estudados, indo ao encontro aos achados de Ranzani e col. ${ }^{9}$, Eurides e col. ${ }^{8}$, Faria e col. ${ }^{6}$, Oliveira e col. ${ }^{7}$ e Mazzanti e col. ${ }^{11}$. Apenas o gato ${ }^{\circ}{ }^{6}$ do G2 não apresentou nenhum tipo de aderência abdominal ou torácico. A formação de aderências entre o enxerto e os órgãos abdominais e torácicos pode ter ocorrido pelo sangramento observado nas bordas do defeito diafragmático e pela reação inflamatória ao fio de sutura presente no local permitindo a formação de aderência fibrosa; esses achados corroboram com os observados por Mazzanti e col. ${ }^{11} \mathrm{e}$, ainda, a manipulação cirúrgica no local pode também ter colaborado para um grande percentual de aderências. Os felinos de $\mathrm{n}^{\mathrm{os}} 3,5$ e 6 do G1 apresentaram aderência de um lobo pulmonar com a linha de incisão da toracotomia e também não demonstraram nenhum sinal de desconforto respiratório durante o tempo de observação.

$\mathrm{Na}$ avaliação microscópica da área de enxertia, nos felinos avaliados aos 30 dias de pós-operatório, observou-se a presença de restos de fio de sutura envoltos por intensa reação pio-granulomatosa. Observou-se também regeneração muscular através da formação de células gigantes, próxima à área de sutura, separadas por grande quantidade de tecido fibrovascular. McGavin ${ }^{16}$ caracteriza esse fenômeno como regeneração por brotamento em que à medida que os mioblastos proliferam e se estendem até a extremidade do tubo rompido, o sarcoplasma protubera de sua extremidade seccionada e toma a forma de clava (claviforme) com numerosos núcleos centrais, formando células musculares gigantes. Os mesmos resultados foram observados nos animais avaliados com 60 dias de pósoperatório, porém, com uma reação inflamatória mais branda e caracterizada pela presença de células musculares ligeiramente basofílicas, núcleos em menor número, centrais e enfileirados; destacando a presença de grande camada de tecido de granulação quando comparada a avaliação microscópica dos animais do G1. Em nenhum dos grupos foi verificada substituição total do enxerto por tecido de granulação, tendo ainda presença de tecido em forma de membrana, bastante resistente, no leito de enxertia. Pelos resultados obtidos não se pode sugerir que, com um tempo maior de observação o enxerto seria substituído totalmente pelo tecido fibrovascular, pois Gallo e col..$^{10}$ verificaram que após cinco meses terem implantado pericárdio de suíno e bovino em defeito diafragmático de cão havia presença do enxerto na área reparada.

\section{Conclusão}

O retalho autólogo de pericárdio pode ser utilizado para reparação de defeito diafragmático de gato doméstico, uma vez que suporta a diferença de pressão do diafragma e é substituído por tecido fibrovascular, sem proliferação exagerada. A sutura contínua simples promove boa vedação do defeito diafragmático durante o período observado.

\section{Referências}

1. Fossum TW. Small animal surgery. In: Surgery of the lower respiratory sistem: pleural cavity and diaphragm. St. Louis: Mosby; 1997. p 675-704.

2. Johnson KA. Hérnia diafragmática, pericárdica e hiatal. In: Slatter D. Manual de cirurgia de pequenos animais. 2ed. São Paulo: Manole; 1998. p 559-577.

3. Mazzanti A, Pippi NL, Raiser AG, Graça DL, Faria RX, Oliveira LO, Silveira AF, Guimarães LD. Implante homólogo de centro tendinoso de ovino conservado em glicerina para reparo de defeito diafragmático em cães. Rev Bras Ciênc Vet 2001;8(2):23-29.

4. Geever ED, Merendino KA. The repair of diaphragmatic defects with cutis grafts: an experimental study. Surg Gynecol Obstet 1952;95:308-16.

5. Schairer AE, Keeley JL. Experimental use of homologus fascia lata to repair diaphragmatic defects in dogs. Surg Gynecol Obstet 1957;105:565-8.

6. Faria RX, Pippi NL, Oliveira LO, Guimarães LD, Mazzanti A, Guedes AGP. Transposição do músculo reto do abdome para correção de defeito iatrogênico no diafragma em cães. Ciênc Rural 2000;30(4):645-9.

7. Oliveira LO, Pippi NL, Graça DL, Faria RX, Guimarães LD, Guedes AGP, Mazzanti A. Retalho pediculado do músculo grande dorsal para reparo de defeito diafragmático experimental em cães. Ciênc Rural 2000;30(6):1005-9.

8. Eurides D, Nigro AJT, Goldenberg S, Novo NF, Juliano Y. Reparo de defeito provocado no diafragma de cães com segmento livre peritônio-muscular: estudo experimental. Acta Cir Bras 1994;9(3):131-5.

9. Ranzani JJT, Gandolfi W, Franco M, Castro GB, Nicoletti JLM. Implante de pericárdio de eqüino preservado em glicerina em solução de continuidade do diafragma de cão. Braz J Vet Res Anim Sci 1990:27(1):65-73.

10. Gallo JI, Artiñano E, Val F, Duran CG. Glutaraldehyde-preseved heterologous pericardium for the repair of diaphragmatic defects. J Thorac Cardiovasc Surg 1982;83(6):905-8.

11. Mazzanti A, Pippi NL, Raiser AG, Graça DL, Silveira AF, Faria RX, Alves AS, Gonçalves GF, Stedile R, Braga FA. Músculo diafragma homólogo conservado em solução supersaturada de 
açúcar para reparação de grande defeito no diafragma de cão. Ciênc Rural 2001;31(2):277-83.

12. Eurides D, Mattos RB, Cassiano W, Dantas MMM. Comportamento do tecido diafragmático nas suturas com fios de algodão e polyvicryl em cães. Rev Bras Med Vet 1987;9:95-6.

13. Cunha O, Pinto Filho STL, Barbosa GS, Raiser AG, Portella LCV. Hérnia peritônio-pericárdica em cão. Ciênc Rural 2000;30(5):905-8.
14. Raiser AG. Herniorrafia diafragmática em cães e gatos: relato de 22 casos e proposição de técnica para corrigir rupturas freno-costais. Braz J Vet Res Anim Sci 1994;31(3/4): 245-51.

15. Burton C, White R. Surgical approach to a ruptured diaphragm in the cat. In Pract 1997;19(6):298-305.

16. Mcgavin MD. Músculos. In: Thomson RG. Patologia veterinária especial. 2ed. Porto Alegre: Artmed; 1998. p 417-47.

$\overline{\text { Pinto Filho ST, Brondani JT, Graça DL, Schossler JE. Reconstruction of feline diaphragm with }}$ autologous pericardium graft. Acta Cir Bras [serial online] 2003 Sept-Oct;18(5). Available from URL: http://www.scielo.br/acb

ABSTRACT - Purpose: Evaluate the use of feline autologous pericardium to correct diaphragmatic defects. Methods: Twelve male and female, adult, mixed breed, domestic cats were used weighing between 2 and 4 kilogram. The surgical procedure consisted of thoracotomy of the $7^{\text {th }}$ left intercostal space, removal of a pericardium graft of approximately $2,0 \times 4,0 \mathrm{~cm}$ and the graft was sutured in a defect of the same size in the diaphragm. Six animals were observed for a period of 30 days postoperatively and six for 60 days. After this period they were submitted to euthanasia for macroscopic observation and sample collection for histological evaluation. Results: Partial substitution of the pericardium was observed 30 days postoperatively, and total substituition 60 days after surgery allowing the complete reestablishment of the diaphragm. Macroscopically, presence of adherence with the lung and parietal pleura and the graft was verified in the thoracic cavity, and with the liver and omentum in the abdominal cavity, however, with no clinical consequences of the involved structures. Conclusion: The autograft in felines can be used to repair diaphragmatic defects, once it supports the gradient of pressure of the diaphragm and it is substituted by connective tissue, without presenting clinical and histological signs of rejection.

KEY WORDS - Thorax. Surgery. Cat. Graft.

Conflito de interesse: nenhum Fonte de financiamento: nenhuma

Correspondência:

Prof. Adj. João Eduardo Schossler

Depto. Clínica de Pequenos Animais

Universidade Federal de Santa Maria - Campus Camobi

97105-900 Santa Maria - RS

schossle@lince.hcv.ufsm.br

Data do recebimento: 10/07/2003

Data da revisão: 18/07/2003

Data da aprovação: 27/07/2003 